\title{
Aberrant expression of CHFR in malignant peripheral nerve sheath tumors
}

\author{
Chikashi Kobayashi ${ }^{1,2}$, Yoshinao Oda ${ }^{1}$, Tomonari Takahira ${ }^{1,2}$, Teiyu Izumi ${ }^{1,2}$, \\ Kenichi Kawaguchi ${ }^{1,2}$, Hidetaka Yamamoto ${ }^{1}$, Sadafumi Tamiya ${ }^{1}$, Tomomi Yamada ${ }^{3}$, \\ Yukihide Iwamoto ${ }^{2}$ and Masazumi Tsuneyoshi ${ }^{1}$
}

${ }^{1}$ Department of Anatomic Pathology, Graduate School of Medical Sciences, Kyushu University, Fukuoka, Japan; ${ }^{2}$ Department of Orthopaedic Surgery, Graduate School of Medical Sciences, Kyushu University, Fukuoka, Japan and ${ }^{3}$ Department of Medical Information Science, Graduate School of Medical Sciences, Kyushu University, Fukuoka, Japan

\begin{abstract}
Mitotic checkpoint maintains genomic integrity before mitosis. Numerous observations have suggested that mitotic abnormalities produce chromosomal instability and aneuploidy. In MPNST, complex karyotypes showing numerical and structural aberrations have been described. 'Checkpoint with forkhead-associated domain and ring finger' (CHFR) was recently identified as defining a new early mitotic checkpoint. We examined the expression of CHFR in 96 cases of MPNST by immunohistochemical and molecular methods. We found reduced (score, $\leqslant 3$ ) expression of CHFR in 63 out of $96(66 \%)$ cases of MPNST, and such alteration was significantly correlated with a high mitotic count, a high Ki-67-labeling index, and a poor prognosis. In addition, MPNST with normal karyotype showed a strong (score, $=5$ ) expression of CHFR. Our results support the assertion that CHFR functions as an inhibitor of tumor proliferation.

Modern Pathology (2006) 19, 524-532. doi:10.1038/modpathol.3800548; published online 10 February 2006
\end{abstract}

Keywords: MPNST; CHFR; prognosis

Malignant peripheral nerve sheath tumor (MPNST) is an uncommon soft-tissue neoplasm with a poor prognosis, occurring sporadically or associated with neurofibromatosis type 1 (NF1). Most MPNSTs arise in association with the major nerve trunk. However, the histogenesis of MPNST remains unclear, especially in sporadic tumors.

In MPNST, complex karyotypes showing numerical and structural changes for virtually all chromosomes have been described. ${ }^{1,2}$ We also detected numerical and structural aberrations of chromosomes in our earlier series. ${ }^{3}$ Most sporadic cancers also have chromosomal aberrations. However, the detailed molecular mechanisms contributing to such aberrations remain widely controversial. A molecular study of MPNST demonstrated frequent alterations of INK4A and P53; $;^{4,5}$ however, such a deficiency of the G1 checkpoint cannot really explain the reason for chromosomal aberration. In fact, a recent study demonstrated that targeted

Correspondence: Dr Y Oda, MD, Department of Anatomic Pathology, Graduate School of Medical Sciences, Kyushu University, 3-1-1 Maidashi, Higashi-ku, Fukuoka 812-8582, Japan. E-mail: oda@surgpath.med.kyushu-u.ac.jp

Received 6 October 2005; revised 21 November 2005; accepted 01 December 2005; published online 10 February 2006 inactivation of the P53 gene does not lead to chromosomal aberration. ${ }^{6}$ Mitotic checkpoint maintains genomic integrity before mitosis, and promotes G2 arrest on detection of DNA damage. Numerous observations have suggested that chromosomal instability is caused by mitotic abnormalities. ${ }^{7,8}$ Some loss in the function of mitotic checkpoint protein such as BUBR1 or MAD2 can cause aneuploidy. ${ }^{9}$ Although impairment of the molecules involved in mitotic checkpoints may be important in tumorigenesis, alterations of already known mitotic checkpoint genes occur very rarely. ${ }^{10,11}$ 'Checkpoint with forkhead-associated domain and ring finger' (CHFR) has recently been identified as defining a new early mitotic checkpoint that delays transition into the metaphase in response to mitotic stress. ${ }^{12}$ Previous studies of various cancers have demonstrated quite frequent inactivation of CHFR. ${ }^{13-17}$ These studies suggest that inactivation of CHFR represents one of the more common molecular defects of a mitotic checkpoint gene.

In the present study, we have examined the expression of CHFR at both the protein level and the mRNA level and we have compared the results with clinicopathological parameters and survival rates. To our knowledge, this is the first investigation of CHFR analysis in MPNST, as well as in soft-tissue sarcoma. 


\section{Materials and methods}

\section{Patients and Tissue Specimens}

Paraffin-embedded tissues from consecutive series of 96 cases of MPNST were obtained from the collection of soft-tissue tumors at the Department of Anatomic Pathology, Pathological Sciences, Graduate School of Medical Sciences, Kyushu University, Japan between 1964 and 2004. A total of 65 tumors were primary tumors, whereas 31 were recurrent tumors at the time of diagnosis. All patients were surgically treated according to the same general approach. The clinicopathological data of the patients are summarized in Table 1. Clinicopathological parameters were classified (eg tumor size, $\geq 5 \mathrm{~cm}$ vs $<5 \mathrm{~cm}$ ) according to previously described criteria. ${ }^{18-20}$ The ages of the patients ranged from 11 months to 86 years (mean, 43.3 years). In all, 40 patients were diagnosed as suffering from NF1 according to the National Institutes of Health (NIH) criteria. $^{21}$ In 42 patients, the tumors occurred in the extremities (thigh, 18; upper arm, 13; lower leg, 7; and forearm, 4), whereas, in 54 patients, the tumors were located in the trunk, head, or neck (chest wall, 7; neck, 7; spinal canal, 7; back, 6; abdominal wall, 6; buttock, 4; retroperitoneum, 4; thoracic cavity, 3; abdominal wall, 3; mediastinum, 2; axilla, 2; head, 2; and groin, 1). Staging was performed only in primary tumors according to the new American Joint Committee on Cancer (AJCC) staging system. ${ }^{22}$ Tumor grading was not performed according to the French Federation of Cancer Centers grading system, because it has been shown to be of no prognostic value in case of MPNST. ${ }^{23}$ Instead, tumors were graded according to the Pediatric Oncology Group Nonrhabdomyosarcoma Soft Tissue Sarcoma (PNRSTS) grading system ${ }^{24}$ in line with that previously described. ${ }^{25}$ Follow-up information was available in 58 out of the 65 primary tumor cases. Median follow-up time was 44 months (range, 1-291 months). Of the 96 cases, 10 were successfully karyotyped and eight cases revealed structural and numerical chromosomal aberrations (Table 2). These 10 patients with MPNST had no previous history of chemotherapy or radiation. We also obtained 10 benign peripheral nerve sheath tumors (BPNSTs), including four sporadic neurofibromas, four neurofibromas arising in NF1 patients, and two neurilemomas, for the purpose of comparison.

Tissues were stained with hematoxylin and eosin for histological examination. Diagnosis in each of the cases was based on histopathological features (proliferation of spindle cells with indistinct cytoplasm margins and wavy nuclei, arranged in fascicles with alternating cellular and myxoid areas), immunohistochemical findings (reactivity for S-100 protein), or clinical evidence (arising in NF1 patients or occurring from a nerve or neurofibroma), as described by Weiss and Goldblum. ${ }^{26}$
Table 1 Clinicopathologic parameters in 96 cases of MPNST

\begin{tabular}{|c|c|}
\hline Parameters & $\mathrm{n}$ \\
\hline \multicolumn{2}{|l|}{ Age (years) } \\
\hline$<50$ & 58 \\
\hline$\geq 50$ & 38 \\
\hline \multicolumn{2}{|l|}{ Sex } \\
\hline Male & 45 \\
\hline Female & 51 \\
\hline \multicolumn{2}{|l|}{$N F 1$} \\
\hline Present & 40 \\
\hline Absent & 56 \\
\hline \multicolumn{2}{|l|}{ Site } \\
\hline Extremities & 42 \\
\hline Trunk, head or neck & 54 \\
\hline \multicolumn{2}{|l|}{ Tumor depth } \\
\hline Superficial & 19 \\
\hline Deep & 77 \\
\hline \multicolumn{2}{|l|}{ Tumor size (cm) } \\
\hline$<5$ & 23 \\
\hline$\geq 5$ & 73 \\
\hline \multicolumn{2}{|l|}{ Presentation } \\
\hline Primary & 65 \\
\hline Recurrent & 31 \\
\hline \multicolumn{2}{|l|}{ Adjuvant therapy } \\
\hline Given & 7 \\
\hline Not given & 89 \\
\hline \multicolumn{2}{|l|}{ Tumor necrosis } \\
\hline No necrosis & 44 \\
\hline$<50 \%$ & 40 \\
\hline$\geq 50 \%$ & 12 \\
\hline \multicolumn{2}{|l|}{ Mitotic count } \\
\hline $0-9 / 10 \mathrm{HPF}^{\mathrm{a}}$ & 59 \\
\hline 10-19/10 HPF & 12 \\
\hline$\geq 20 / 10 \mathrm{HPF}$ & 25 \\
\hline \multicolumn{2}{|l|}{ Ki-67-labeling index } \\
\hline $0-9 \%$ & 30 \\
\hline $10-29 \%$ & 41 \\
\hline$\geq 30 \%$ & 25 \\
\hline \multicolumn{2}{|l|}{ Rhabdoid cells } \\
\hline Present & 18 \\
\hline Absent & 78 \\
\hline \multicolumn{2}{|l|}{ Epithelioid cells } \\
\hline Present & 10 \\
\hline Absent & 86 \\
\hline \multicolumn{2}{|l|}{ PNRSTS grading } \\
\hline 1 & 25 \\
\hline 2 & 5 \\
\hline 3 & 66 \\
\hline \multicolumn{2}{|l|}{ AJCC stage ${ }^{\mathrm{b}}$} \\
\hline $\mathrm{I}$ & 12 \\
\hline II & 15 \\
\hline III & 37 \\
\hline IV & 1 \\
\hline
\end{tabular}

HPF, high-power field; NF1, neurofibromatosis type 1; AJCC, American Joint Committee on Cancer; PNRSTS, Pediatric Oncology Group Nonrhabdomyosarcoma Soft Tissue Sarcoma.

${ }^{\mathrm{a}}$ An HPF measures $0.1734 \mathrm{~mm}^{2}$.

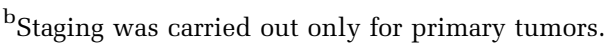


Table 2 Karyotypes of MPNSTs

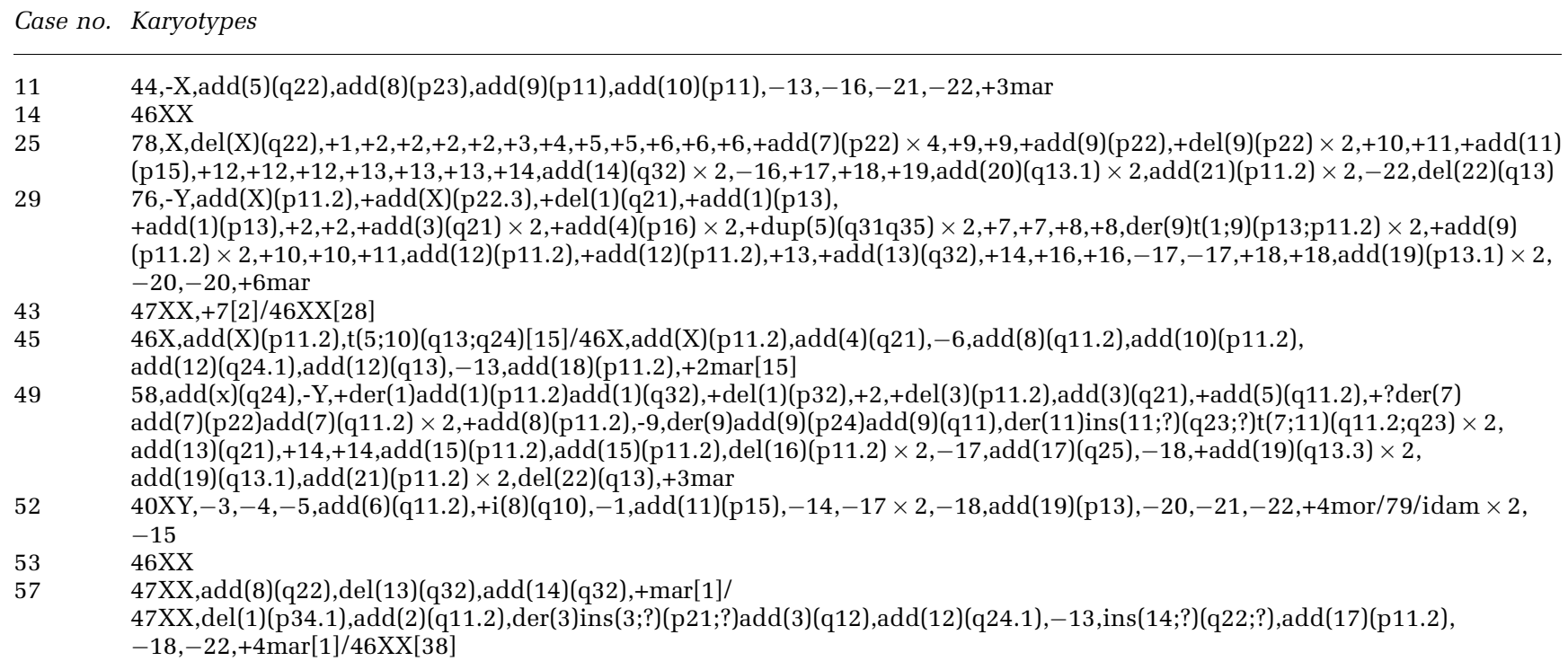

In addition, snap-frozen samples from seven primary tumors, for which normal adjacent tissue was available, were obtained from the MPNST panel. All these samples were obtained during surgical procedures. We confirmed that they had not previously received any other forms of therapy.

\section{Immunohistochemistry}

Sections (4- $\mu \mathrm{m}$ thick) were deparaffinized and dehydrated through xylene and ethanol. After the endogenous peroxidase activity was blocked by methanol containing $0.3 \%$ hydrogen peroxidase for $30 \mathrm{~min}$, the sections were microwaved in $0.01 \mathrm{~mol} / \mathrm{l}$ citrate buffer with $0.01 \%$ Tween (pH 6.0) for 20 min for heat-based antigen retrieval. The slides were exposed to $10 \%$ nonimmunized rabbit serum in phosphate-buffered saline (PBS) for $10 \mathrm{~min}$, and then the sections were incubated overnight at $4{ }^{\circ} \mathrm{C}$ with goat polyclonal antibody against CHFR (sc-13288, 1:50; Santa Cruz Biotechnology, CA, USA). The labeled antigen was detected by a HistoFine Kit (Nichirei Pharmaceutical, Tokyo, Japan) and visualized by the 3,3'-diaminobenzidine tetrahydrochloride as a chromogen, accompanied by counterstaining with hematoxylin. The serial paraffin sections were also immunostained with a Ki-67 mouse monoclonal antibody (M 7240, 1:100; Dako, Copenhagen, Denmark) using the same procedure as for the CHFR staining. In each experiment, sections were treated similarly with PBS instead of the primary antibody as negative controls. Intact staining of adjacent normal tissue such as skin tissue or vessels served as an internal positive control.

Because CHFR is a nuclear protein and is localized within the nucleus, ${ }^{27}$ we focused on its nuclear expression. The nuclear expression of CHFR was assessed semiquantitatively, with the percentage and intensity of stained cells compared with the adjacent normal tissue. At least 1000 tumor cells were counted in each case. The percentage of CHFRpositive cells was graded from 0 to $2(0=<10 \%$ of positive cells; $1=10-49 \% ; 2=\geq 50 \%$ ). The overall intensity of staining was assessed as follows: 0, no staining; 1, weak staining; 2, moderate staining (equivalent to normal tissue); 3, strong staining. The final score was calculated by adding the scores for the percentage and the intensity. Tumors were evaluated as 'reduced' when the final score was $\leq 3$ and as 'preserved' when the score was otherwise. In addition, when the score was 5, tumors were considered as demonstrating strong expression. The Ki-67-labeling index was estimated by counting the number of positive cells/1000 tumor cells. All the hematoxylin and eosin-stained slides and the immunohistochemical slides were evaluated independently by three observers (CK, YO, and MT), and the grading was evaluated without knowledge of the clinical outcome.

\section{RNA Extraction and Reverse Transcription-Polymerase Chain Reaction}

Total RNA was extracted with $1 \mathrm{ml}$ of TRIzol reagent (Invitrogen, CA, USA) from snap-frozen tumor samples, from corresponding normal tissues, and from an osteosarcoma cell line (SAOS2) according to the manufacturer's instructions. Osteosarcoma cell line SAOS2, which expresses wild-type CHFR, ${ }^{12}$ was used as a positive control. To avoid contamination as much as possible, we confirmed that the tumor or normal tissue was not contaminated in each of the samples, with reference to their concordant HE-stained slides. 
Total RNA ( $5 \mu \mathrm{g}$ ) from each of the samples were reverse-transcribed using Superscript III reverse transcriptase (Invitrogen, CA, USA) in order to prepare first-strand cDNA. The reverse transcription-polymerase chain reaction (RT-PCR) was performed using primers and temperature profiles, as previously described (Table 3). ${ }^{13}$ Negative controls consisted of RNA which had been treated identically but without the addition of reverse transcriptase. The PCR products were electrophoresed on $2 \%$ agarose gel with ethidium bromide staining. Realtime PCR was carried out using ABsolute ${ }^{\mathrm{TM}}$ QPCR SYBR Green Mixes (ABgene, Surrey, UK) in a solution containing $100 \mathrm{ng}$ of cDNA, $25 \mu \mathrm{l}$ of SYBR Green Mix, and 3.5 pmol of each of the primers. The primers used are summarized in Table 3 , and were as described previously. ${ }^{16,28}$ The PCR cycling protocol included one cycle at $95^{\circ} \mathrm{C}$ for $10 \mathrm{~min}$, followed by 40 cycles at $95^{\circ} \mathrm{C}$ for $15 \mathrm{~s}$ and at $60^{\circ} \mathrm{C}$ for $1 \mathrm{~min}$. Fluorescent signals were detected using an ABI Prism 7700 (Applied Biosystems, CA, USA). Data were analyzed using ABI Prism 7700 SDS Software (also Applied Biosystems). Standard curves were generated using serial dilutions of Human Total RNA (BD Biosciences Clontech, NJ, USA). Ratios of the intensities of the CHFR and GAPDH signals were used as a relative measure of the expression level of CHFR mRNA in each specimen.

\section{Statistics}

The correlation between the immunohistochemical expression of CHFR and the clinicopathologic parameters was assessed by $t$-test, $\chi^{2}$-square test, and Fisher's exact test. Association between CHFR mRNA expression and CHFR immunohistochemical expression status was examined using MannWhitney's $U$-test. The clinical outcomes of the MPNST patients were followed between surgery and the date of the last follow-up or the date of death by disease. Survival analysis was carried out only for those groups of patients with primary tumors, while patients who were alive or who had died of other causes were censored. Overall survival was estimated by the Kaplan-Meier method with the log-rank test. Multivariate analysis was performed using the Cox proportional hazards model with the stepwise method. A two-sided $P$-value of $<0.05$ was considered statistically significant. All tests were carried out in consultation with a biostatistician.

\section{Results} Correlation between CHFR Immunohistochemical
Expression and Clinicopathological Parameters

CHFR immunoreactivity in the normal skin tissue is presented in Figure 1a. In normal tissue, CHFR expression was detected mainly in the nucleus $($ score $=4)$ and partly in the cytoplasm, but no membranous staining was found.

The correlation between CHFR immunoreactivity and the clinicopathological parameters is presented in Table 4. The nuclear expression was reduced in 63 of the $96(66 \%)$ MPNST cases (Figure 1b), whereas in the remaining $33(34 \%)$ it was preserved (Figure 1c). In contrast, all the BPNSTs showed preserved expression (Figure 1d). Reduced expression of CHFR was significantly correlated with young age $(P=0.0200)$, site of trunk, head or neck $(P=0.0160)$, presentation in the recurrent tumor $(P=0.0093)$, a high mitotic count $(P=0.0023)$, and a high Ki-67-labeling index $(P=0.0064)$. There was a trend toward a correlation between reduced CHFR expression and deep tumor location $(P=0.0614)$; however, this finding was not statistically significant.

Focusing on the karyotyping data, two (20\%) MPNST cases with normal karyotype showed a strong (score, $\geq 5$ ) expression, while eight $(80 \%)$ with chromosomal aberration did not (score, $\leq 4$, $P=0.0222$ ) (Table 5).

\section{RT-PCR Analysis}

CHFR mRNA levels were examined in seven normal tissue and in seven tumor tissue-paired MPNST samples. CHFR was expressed at detectable levels in

Table 3 PCR primer sequences used

\begin{tabular}{|c|c|c|c|c|}
\hline Primers & Sequences & & Annealing temperature $\left({ }^{\circ} \mathrm{C}\right)$ & Product size (bp) \\
\hline \multicolumn{5}{|l|}{$R T-P C R$} \\
\hline CHFR cDNA & $\begin{array}{l}\text { Sense: } \\
\text { Antisense: }\end{array}$ & $\begin{array}{l}5^{\prime} \text {-AGCTCAACCTGGGTGACAAG-3' } \\
5^{\prime} \text {-TAGGTCAGCTCACGGAAGCT-3' }\end{array}$ & 60 & 229 \\
\hline GAPDH cDNA & $\begin{array}{l}\text { Sense: } \\
\text { Antisense: }\end{array}$ & $\begin{array}{l}\text { 5'-AATCAAGTGGGGCGATGCTG-3' }^{\prime} \\
5^{\prime} \text {-GCAGAGATGATGACCCTTTTG-3' }\end{array}$ & 55 & 118 \\
\hline \multicolumn{5}{|l|}{ Real-time PCR } \\
\hline CHFR cDNA & $\begin{array}{l}\text { Sense: } \\
\text { Antisense: }\end{array}$ & $\begin{array}{l}5^{\prime} \text {-CCTCAACAACCTCGTGGAAGCATAC-3' } \\
5^{\prime} \text {-TCCTGGCATCCATACTTTGCACATC-3' }\end{array}$ & 60 & 86 \\
\hline GAPDH cDNA & $\begin{array}{l}\text { Sense: } \\
\text { Antisense: }\end{array}$ & $\begin{array}{l}5^{\prime} \text {-CGTGGAAGGACTCATGACCA-3' } \\
5^{\prime} \text {-GCCATCACGCCACAGTTTC-3' }\end{array}$ & 60 & 87 \\
\hline
\end{tabular}



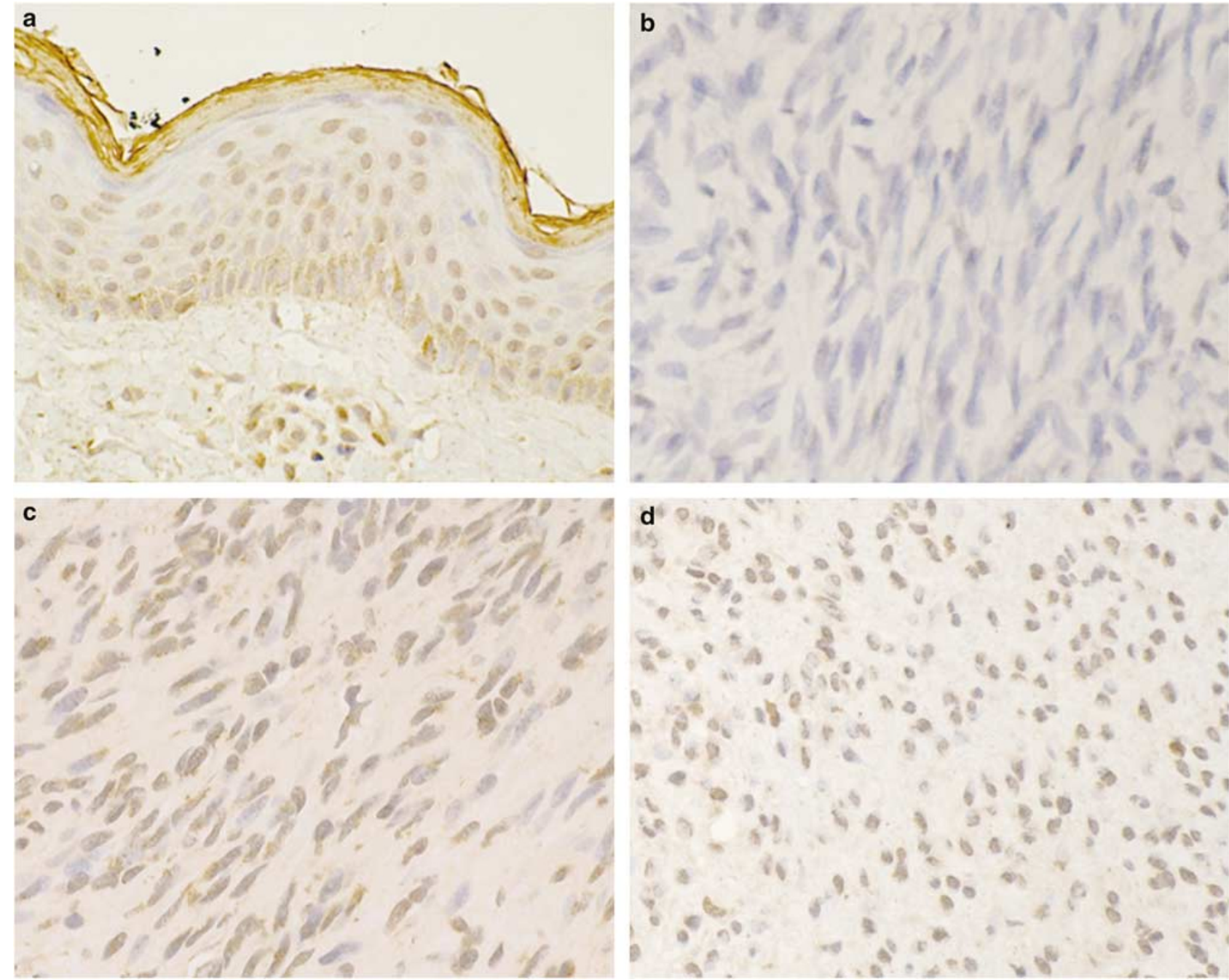

Figure 1 Immunohistochemical results of CHFR. (a) CHFR expression is detected mainly in the nucleus of normal skin tissue (score $=4$ ). (b) Reduced expression in MPNST, Case 9 (score=1). This case died of disease 18 months after the operation. (c) Preserved nuclear expression in MPNST, Case 11 (score =4). The patient is alive and well 3 years after the operation. (d) Preserved nuclear expression in BPNST, neurofibroma arising in an NF1 patient (score $=4$ ).

all of the seven normal tissue samples and in four of the seven (57\%) MPNST samples (Figure 2). SAOS2, an osteosarcoma cell line used as a positive control, also showed CHFR mRNA expression. However, the remaining three (43\%) MPNST samples showed no, or only negligible, mRNA expression. The data with real-time PCR were matched with data obtained with RT-PCR, and were found to be significantly associated with the immunohistochemical data $(P=0.0339)$ (Figure 3$)$.

\section{Univariate and Multivariate Analysis of Prognostic Parameters}

The results of univariate and multivariate analysis of the prognostic factors for overall survival in 58 patients with primary tumors are shown in Table 6. In the univariate analysis, poor prognosis was found to be significantly correlated with the presence of NF1 $(P=0.0152)$, deep tumor situation $(P=0.0311)$, tumor size of $\geq 5 \mathrm{~cm}(P=0.0485)$, the presence of tumor necrosis $(P=0.0266), \geq 20$ mitoses per 10 HPF $(P=0.0075)$, a Ki-67-labeling index of $\geq 30 \%$ $(P=0.0488)$, a PNRSTS grade of $\geq 2(P=0.0376)$, an AJCC stage of $\geq$ III $(P=0.0051)$, and reduced CHFR immunohistochemical expression $(P=0.0072)$. An advanced age of more than 50 years demonstrated a trend toward a correlation with poor prognosis $(P=0.0686)$, but this finding was not statistically significant. The immunohistochemical expression of CHFR and Kaplan-Meier survival estimates are shown in Figure 4. Patients with reduced CHFR expression had a significantly worse prognosis than those with preserved expression. The prognostic parameters and CHFR immunohistochemical expression were also analyzed using multivariate analysis. In the multivariate analysis, AJCC stage 
Table 4 Immunohistochemical expression of CHFR according to clinicopathologic features

\begin{tabular}{|c|c|c|c|}
\hline \multirow[t]{2}{*}{ Clinicopathologic findings } & \multicolumn{2}{|c|}{ Expression of CHFR } & \multirow[t]{2}{*}{ P-value } \\
\hline & Reduced & Preserved & \\
\hline Age (years, mean \pm s.d.) & $39.8 \pm 19.5$ & $50.0 \pm 21.2$ & 0.0200 \\
\hline \multicolumn{4}{|l|}{ Sex } \\
\hline Male $(n=45)$ & 31 & 14 & \\
\hline Female $(n=51)$ & 32 & 19 & NS \\
\hline \multicolumn{4}{|l|}{$N F 1$} \\
\hline Present $(n=40)$ & 29 & 11 & \\
\hline Absent $(n=56)$ & 34 & 22 & NS \\
\hline \multicolumn{4}{|l|}{ Site } \\
\hline Extremities $(n=42)$ & 22 & 20 & \\
\hline $\begin{array}{l}\text { Trunk, head or } \\
\text { neck }(n=54)\end{array}$ & 41 & 13 & 0.0160 \\
\hline \multicolumn{4}{|l|}{ Tumor depth } \\
\hline Superficial $(n=19)$ & 9 & 10 & \\
\hline Deep $(n=77)$ & 54 & 23 & NS (0.0614) \\
\hline \multicolumn{4}{|l|}{ Tumor size } \\
\hline$<5 \mathrm{~cm}(n=23)$ & 17 & 6 & \\
\hline$\geq 5 \mathrm{~cm}(n=73)$ & 46 & 27 & NS \\
\hline \multicolumn{4}{|l|}{ Presentation } \\
\hline Primary $(n=65)$ & 37 & 28 & \\
\hline Recurrent $(n=31)$ & 26 & 5 & 0.0093 \\
\hline \multicolumn{4}{|l|}{ Adjuvant therapy } \\
\hline Given $(n=7)^{2}$ & 5 & 2 & \\
\hline Not given $(n=89)$ & 58 & 31 & NS \\
\hline \multicolumn{4}{|l|}{ Tumor necrosis } \\
\hline No necrosis $(n=44)$ & 28 & 16 & \\
\hline$<50 \%(n=40)$ & 26 & 14 & \\
\hline$\geq 50 \%(n=12)$ & 9 & 3 & NS \\
\hline \multicolumn{4}{|l|}{ Mitotic count } \\
\hline $0-9 / 10 \mathrm{HPF}^{\mathrm{a}}(n=59)$ & 32 & 27 & \\
\hline $10-19 / 10 \mathrm{HPF}(n=12)$ & 9 & 3 & \\
\hline$\geq 20 / 10 \mathrm{HPF}(n=25)$ & 22 & 3 & 0.0090 \\
\hline \multicolumn{4}{|l|}{ Ki-67-labeling index } \\
\hline $0-9 \%(n=30)$ & 14 & 16 & \\
\hline $10-29 \%(n=41)$ & 28 & 13 & \\
\hline$\geq 30 \%(n=25)$ & 21 & 4 & 0.0132 \\
\hline \multicolumn{4}{|c|}{ Rhabdomyoblasts (malignant Triton tumor) } \\
\hline Present $(n=18)$ & 14 & 4 & \\
\hline Absent $(n=78)$ & 49 & 29 & NS \\
\hline \multicolumn{4}{|l|}{ Epithelioid cells } \\
\hline Present $(n=10)$ & 6 & 4 & \\
\hline Absent $(n=86)$ & 57 & 29 & NS \\
\hline \multicolumn{4}{|l|}{ PNRSTS grading } \\
\hline $1(n=25)$ & 14 & 11 & \\
\hline $2(n=5)$ & 2 & 3 & \\
\hline $3(n=66)$ & 47 & 19 & NS \\
\hline \multicolumn{4}{|l|}{ AJCC stage ${ }^{\mathrm{b}}$} \\
\hline $\mathrm{I}(n=12)$ & 7 & 5 & \\
\hline II $(n=15)$ & 8 & 7 & \\
\hline III $(n=37)$ & 22 & 15 & \\
\hline IV $(n=1)$ & 0 & 1 & NS \\
\hline
\end{tabular}

NS, statistically not significant; HPF, high-power field; NF1, neurofibromatosis type 1; AJCC, American Joint Committee on Cancer; PNRSTS, Pediatric Oncology Group Nonrhabdomyosarcoma Soft Tissue Sarcoma.

${ }^{\mathrm{a}}$ An HPF measures $0.1734 \mathrm{~mm}^{2}$.

${ }^{\mathrm{b}}$ Staging was carried out only for primary tumors.
Table 5 Immunohistochemical expression of CHFR according to chromosomal aberration

\begin{tabular}{lccc}
\hline & \multicolumn{2}{c}{ Expression of CHFR } & P-value \\
\cline { 2 - 3 } & Strong (score $=5)$ & Otherwise (score $\leq 4)$ & \\
\hline Present $(n=8)$ & 0 & 8 & \\
Absent $(n=2)$ & 2 & 0 & 0.0222 \\
\hline
\end{tabular}

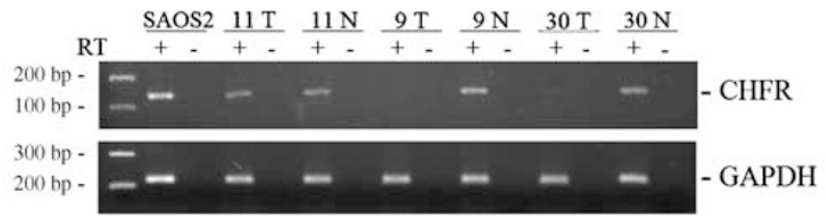

Figure 2 Analysis of CHFR mRNA expression by RT-PCR. Controls consisted of carrying out PCR in the absence of RT and amplification of GAPDH to assess the quality of the cDNA. CHFR was expressed at detectable levels in SAOS2 (positive control), tumor tissue of Case 11, and all normal tissue. Tumor tissue of Case 9 and Case 30 showed no mRNA expression. T, tumor tissue; $\mathrm{N}$, normal tissue.

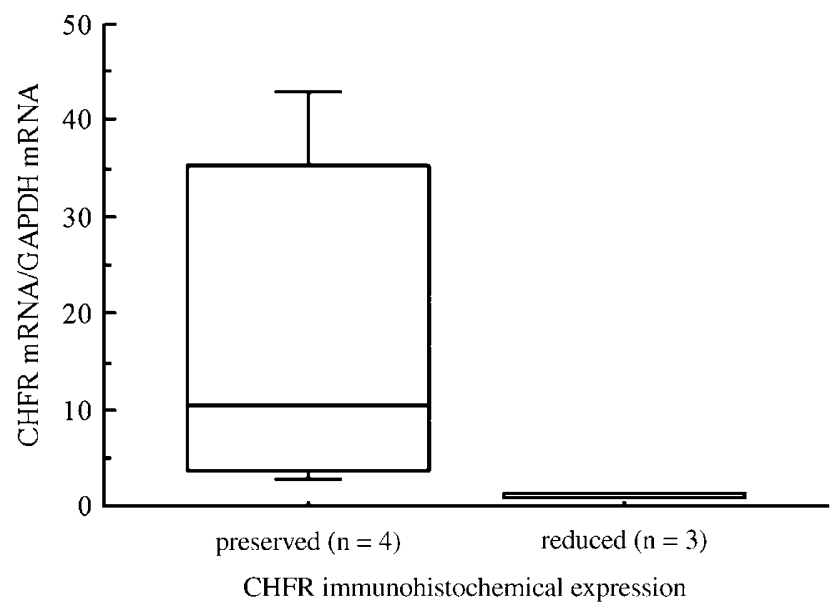

Figure 3 Correlation between CHFR mRNA expression and CHFR immunohistochemical expression status. Box indicates 75 and 25 percentile, horizontal line indicates the median, and bars indicate 10 and 90 percentile. CHFR immunohistochemical expression status was significantly correlated with CHFR mRNA expression ( $P=0.0339$, Mann-Whitney's $U$-test).

of $\geq$ III $(P=0.0010)$ and reduced CHFR immunohistochemical expression $(P=0.0016)$ emerged as independent predictors of poor prognosis.

\section{Discussion}

CHFR is expressesed ubiquitously in normal human tissue. ${ }^{12}$ In this study, a reduced expression of CHFR protein was recognized only in malignant tumors. Both BPNSTs and normal tissue showed preserved expression. 
Table 6 Multivariate and univariate analysis for overall survival

\begin{tabular}{|c|c|c|c|}
\hline \multirow[t]{2}{*}{ Parameters } & \multirow{2}{*}{$\begin{array}{l}\text { Univariate } \\
\text { analysis } \\
\text { (P-value) }\end{array}$} & \multicolumn{2}{|c|}{ Multivariate analysis } \\
\hline & & Hazard ratio (95\% CI) & P-value \\
\hline \multicolumn{4}{|l|}{ Age (years) } \\
\hline \multicolumn{4}{|l|}{$<50(n=33)$} \\
\hline$\geq 50(n=25)$ & $\begin{array}{c}\text { NS } \\
(0.0686)\end{array}$ & & NS \\
\hline \multicolumn{4}{|l|}{ Sex } \\
\hline \multicolumn{4}{|l|}{ Male $(n=27)$} \\
\hline Female $(n=31)$ & NS & & NS \\
\hline \multicolumn{4}{|l|}{$N F 1$} \\
\hline \multicolumn{4}{|l|}{ Present $(n=21)$} \\
\hline Absent $(n=37)$ & 0.0152 & & NS \\
\hline \multicolumn{4}{|l|}{ Site $\ldots$} \\
\hline \multicolumn{4}{|l|}{$\begin{array}{l}\text { Extremities } \\
(n=31)\end{array}$} \\
\hline $\begin{array}{l}\text { Trunk, head and } \\
\text { neck }(n=27)\end{array}$ & NS & & NS \\
\hline \multicolumn{4}{|l|}{ Tumor depth } \\
\hline \multicolumn{4}{|l|}{$\begin{array}{l}\text { Superficial } \\
(n=10)\end{array}$} \\
\hline Deep $(n=48)$ & 0.0311 & & NS \\
\hline \multicolumn{4}{|l|}{ Tumor size } \\
\hline \multirow{2}{*}{$\begin{array}{l}<5 \mathrm{~cm}(n=12) \\
\geq 5 \mathrm{~cm}(n=46)\end{array}$} & & & \\
\hline & 0.0485 & & NS \\
\hline \multicolumn{4}{|l|}{ Adjuvant therapy } \\
\hline \multicolumn{4}{|l|}{ Given $(n=2)$} \\
\hline Not given $(n=56)$ & NS & & NS \\
\hline \multicolumn{4}{|l|}{ Tumor necrosis } \\
\hline \multicolumn{4}{|l|}{ Present $(n=31)$} \\
\hline Absent $(n=27)$ & 0.0266 & & NS \\
\hline \multicolumn{4}{|l|}{ Mitotic count } \\
\hline \multicolumn{4}{|l|}{$\begin{array}{l}0-19 / 10 \mathrm{HPF} \\
(n=47)\end{array}$} \\
\hline \multicolumn{4}{|l|}{$\begin{array}{l}\geq 20 / 10 \mathrm{HPF} \\
(n=11)\end{array}$} \\
\hline \multicolumn{4}{|l|}{ Ki-67-labeling index } \\
\hline$<30 \%(n=45)$ & & & \\
\hline$\geq 30 \%(n=13)$ & 0.0488 & & NS \\
\hline Rhabdomyoblasts (m & alignant Trit & on tumor) & \\
\hline Present $(n=10)$ & & & \\
\hline Absent $(n=48)$ & NS & & NS \\
\hline Epithelioid cells & & & \\
\hline Present $(n=5)$ & & & \\
\hline Absent $(n=53)$ & NS & & NS \\
\hline PNRSTS grading & & & \\
\hline $1(n=16)$ & & & \\
\hline $2+3(n=42)$ & 0.0376 & & NS \\
\hline AJCC stage & & & \\
\hline I+II $(n=22)$ & & 1 & \\
\hline $\mathrm{III}+\mathrm{IV}(n=36)$ & 0.0051 & $4.783(1.878-12.181)$ & 0.0010 \\
\hline CHFR immunohistoc & hemical expr & ession & \\
\hline Preserved $(n=24)$ & & 1 & \\
\hline Reduced $(n=34)$ & 0.0072 & $4.751(1.800-12.531)$ & 0.0016 \\
\hline
\end{tabular}

HPF, high-power field; NS, nonsignificant; NF1, neurofibromatosis type 1; AJCC, American Joint Committee on Cancer; PNRSTS, Pediatric Oncology Group Nonrhabdomyosarcoma Soft Tissue Sarcoma.

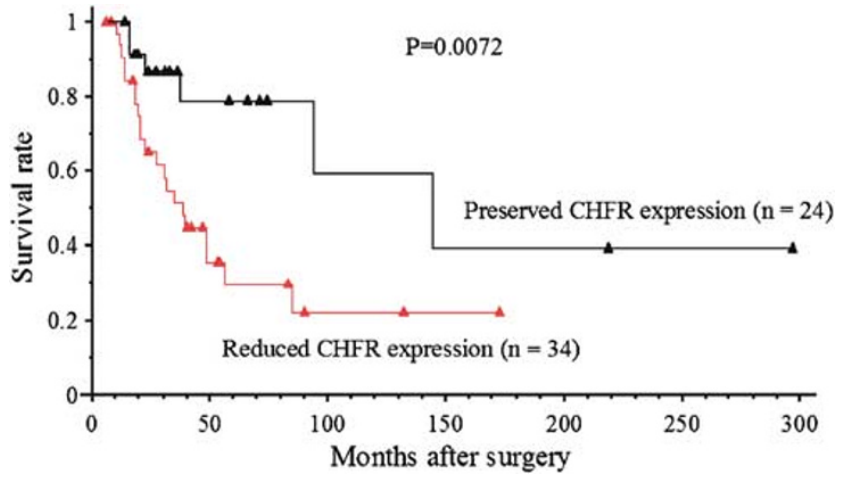

Figure 4 Kaplan-Meier overall survival curves of patients with MPNST according to CHFR immunohistochemical expression status. Censored cases are plotted. Overall survival rate of patients with preserved expression of CHFR is significantly higher than that of patients with reduced expression.

Although the sample size is small, we found that MPNST with normal karyotype showed a strong expression of CHFR. Chaturvedi et $a l^{29}$ demonstrated in their preliminary studies that the expression of CHFR protein is cell cycle dependent. If the normal function of CHFR as a mitotic checkpoint protein is preserved, its expression increases in response to mitotic stress. Thus, it is suggested that the expression of CHFR may be activated and may increase in response to the high proliferative activity of the malignant tumor, when the normal function of CHFR is preserved. If we assume that a strong expression of CHFR reflects such an increase as a normal response, then we can explain the intact karyotype of MPNST which strongly expressed CHFR, on the grounds that MPNST with an intact karyotype may retain the normal function of CHFR, and the normal increase of CHFR may play a role in ensuring chromosomal stability.

We found a significant association between the reduced expression of CHFR and a high mitotic count. This finding was in agreement with a previous study reporting an association between the expression of CHFR and mitosis. ${ }^{12}$ It is suggested that alteration of CHFR is involved in the mitotic checkpoint impairment. Another important point is that a high mitotic count means high proliferative activity; there is the possibility that a reduction of CHFR causes accelerated tumor cell proliferation. Furthermore, MPNST with a reduction of CHFR revealed a high Ki-67-labeling index. According to these two experimental results about proliferative activity, it is would seem that CHFR act as an inhibitor of tumor proliferation. Because CHFR defines a mitotic checkpoint, it is naturally assumed that CHFR inhibits tumor proliferation. In this study, multivariate survival analysis showed that the reduced expression of CHFR was an independent predictor of poor prognosis. Accordingly, it is thus possible to build up a hypothesis that CHFR is an inhibitor of tumor proliferation and that the alteration of CHFR results in chromosomal aberra- 
tion and promotes tumorigenesis in MPNST. Recently, $\mathrm{Yu}$ et $a l^{30}$ demonstrated that CHFR physically interacts and ubiquitinates the mitotic kinase Aurora-A, which has an oncogenic charac$\operatorname{ter}^{31}$ and which is frequently upregulated in a variety of tumors. ${ }^{32,33}$ Overexpression of Aurora-A can cause aneuploidy. ${ }^{34} \mathrm{Yu}$ et $a l^{30}$ also generated CHFR knockout mice and suggested that CHFR is a tumor suppressor that ensures chromosomal stability. Our experimental results agree with those obtained by them and support their conclusion.

The average age of the patients who had reduced CHFR expression was significantly lower than that of those who had preserved expression. It seems reasonable to suppose that inactivation of CHFR in MPNST is not age-related. Interestingly, some investigators have demonstrated that promoter hypermethylation of CHFR was age-related in normal colonic mucosa, but not age-related in lung tissue or gastric mucosa. ${ }^{15,16}$ Promoter hypermethylation is one of the major causes behind the inactivation of CHFR; epigenetic inactivation of CHFR has been detected at a variable rate in other tumors. ${ }^{13-17}$ A study of methylation lies outside the scope of the persent paper, but it does warrant further investigation.

The reduced expression of CHFR was significantly more frequent in MPNST arising in the nonextremities. As mentioned above, CHFR turned out to be a tumor suppressor. It seems therefore reasonable to suppose that MPNSTs arising in the nonextremities and those arising in the extremities may develop via separate molecular pathways. A previous larger study showed a significant association between location in the nonextremities and poor prognosis, ${ }^{35}$ although the statistical analysis in the current study omitted 'tumor site' from among the prognostic factors. As for other sarcomas, welldifferentiated lipoma-like liposarcoma has a different status of P53 and MDM2 immunohistochemical expression according to tumor site, and also has a different clinical outcome according to tumor site. ${ }^{36}$ A difference in location sometimes leads to a difference in character for the same entity. In view of our results, there remains the possibility that MPNST is also divided into two different categories.

We also found that recurrent MPNST showed more a frequent reduction of CHFR. It may follow that the alteration of CHFR accumulates as the tumor progresses, or that the alteration of CHFR is an event which occurs late in the tumorigenesis of MPNST. Additionally, as is the case with MPNST arising in the non-extremities, experience tells us that recurrent MPNST also carries with it a poor prognosis. Thus, the above statistical results with regard to tumor site and recurrence may also have a close link to the fact that the reduced expression of CHFR was an independent predictor of poor prognosis.

Mitotic checkpoint dysfunction is associated with sensitivity to microtubule inhibitory chemothera- peutic drugs. Tumors with reduced CHFR expression may be more sensitive to microtubule inhibitors because of checkpoint failure. Although further studies are necessary, there is a possibility that the immunohistochemical expression of CHFR is a marker of responsiveness to microtubule inhibitors, such as paclitaxel.

In conclusion, we found altered expression of CHFR protein in 63 out of $96(66 \%)$ cases of MPNST, and such alteration was significantly correlated with a high mitotic count, a high Ki-67-labeling index, and a poor prognosis. Our results support the assertion that CHFR functions as a tumor suppressor.

\section{Acknowledgements}

The English used in this manuscript was revised by Miss K Miller (Royal English Language Centre, Fukuoka, Japan). This work was supported in part by a Grant-in-Aid for Scientific Research from the Japan Society of the Promotion of Science (15590304), Tokyo, Japan.

\section{References}

1 Plaat BE, Molenaar WM, Mastik MF, et al. Computerassisted cytogenetic analysis of 51 malignant peripheral-nerve-sheath tumors: sporadic vs neurofibromatosis-type-1-associated malignant schwannomas. Int J Cancer 1999;83:171-178.

2 Mertens F, Dal CinP, De Wever I, et al. Cytogenetic characterization of peripheral nerve sheath tumours: a report of the CHAMP study group. J Pathol 2000; 190:31-38.

3 Kobayashi C, Oda Y, Takahira T, et al. Chromosomal aberration and microsatellite instability of malignant peripheral nerve sheath tumors: a study of 10 tumors from 9 patients. Cancer Genet Cytogenet, in press.

4 Perrone F, Tabano S, Colombo F, et al. p15INK4b, p14ARF, and p16INK4a inactivation in sporadic and neurofibromatosis type 1-related malignant peripheral nerve sheath tumors. Clin Cancer Res 2003;9: 4132-4138.

5 Birindelli S, Perrone F, Oggionni M, et al. Rb and TP53 pathway alterations in sporadic and NF1-related malignant peripheral nerve sheath tumors. Lab Invest 2001;81:833-844.

6 Bunz F, Fauth C, Speicher MR, et al. Targeted inactivation of p53 in human cells does not result in aneuploidy. Cancer Res 2002;62:1129-1133.

7 Paulovich AG, Toczyski DP, Hartwell LH. When checkpoints fail. Cell 1997;88:315-321.

8 Cahill DP, Lengauer C, Yu J, et al. Mutations of mitotic checkpoint genes in human cancers. Nature 1998;392: 300-303.

9 Kops GJ, Foltz DR, Cleveland DW. Lethality to human cancer cells through massive chromosome loss by inhibition of the mitotic checkpoint. Proc Natl Acad Sci USA 2004;101:8699-8704.

10 Haruki N, Saito H, Harano T, et al. Molecular analysis of the mitotic checkpoint genes BUB1, BUBR1 and 
BUB3 in human lung cancers. Cancer Lett 2001; 162:201-205.

11 Gemma A, Hosoya Y, Seike M, et al. Genomic structure of the human MAD2 gene and mutation analysis in human lung and breast cancers. Lung Cancer 2001; 32:289-295.

12 Scolnick DM, Halazonetis TD. Chfr defines a mitotic stress checkpoint that delays entry into metaphase. Nature 2000;406:430-435.

13 Shibata Y, Haruki N, Kuwabara Y, et al. Chfr expression is downregulated by $\mathrm{CpG}$ island hypermethylation in esophageal cancer. Carcinogenesis 2002;23: 1695-1699.

14 Bertholon J, Wang Q, Falette N, et al. Chfr inactivation is not associated to chromosomal instability in colon cancers. Oncogene 2003;22:8956-8960.

15 Corn PG, Summers MK, Fogt F, et al. Frequent hypermethylation of the $5^{\prime} \mathrm{CpG}$ island of the mitotic stress checkpoint gene Chfr in colorectal and nonsmall cell lung cancer. Carcinogenesis 2003;24:47-51.

16 Satoh A, Toyota M, Itoh F, et al. Epigenetic inactivation of CHFR and sensitivity to microtubule inhibitors in gastric cancer. Cancer Res 2003;63:8606-8613.

17 Toyota M, Sasaki Y, Satoh A, et al. Epigenetic inactivation of CHFR in human tumors. Proc Natl Acad Sci USA 2003;100:7818-7823.

18 Trojani M, Contesso G, Coindre JM, et al. Soft-tissue sarcomas of adults; study of pathological prognostic variables and definition of a histopathological grading system. Int J Cancer 1984;33:37-42.

19 Guillou L, Coindre JM, Bonichon F, et al. Comparative study of the National Cancer Institute and French Federation of Cancer Centers Sarcoma Group grading systems in a population of 410 adult patients with soft tissue sarcoma. J Clin Oncol 1997;15:350-362.

20 Hasegawa T, Yokoyama R, Lee YH, et al. Prognostic relevance of a histological grading system using MIB-1 for adult soft-tissue sarcoma. Oncology 2000;58:66-74.

21 National Institute of Health. Neurofibromatosis. Conference statement. National Institutes of Health Consensus Development Conference. Arch Neurol 1998;45:575-578.

22 Fleming ID, Cooper JS, Henson DE, et al (eds). American Joint Committee on Cancer (AJCC). AJCC Cancer Staging Manual, 5th edn. J.B. Lippincott: Philadelphia, 1997.

23 Coindre JM, Terrier P, Guillou L, et al. Predictive value of grade for metastasis development in the main histologic types of adult soft tissue sarcomas: a study of 1240 patients from the French Federation of Cancer Centers Sarcoma Group. Cancer 2001;91: 1914-1926.
24 Parham DM, Webber BL, Jenkins III JJ, et al. Nonrhabdomyosarcomatous soft tissue sarcomas of childhood: formulation of a simplified system for grading. Mod Pathol 1995;8:705-710.

25 Zhou H, Coffin CM, Perkins SL, et al. Malignant peripheral nerve sheath tumor: a comparison of grade, immunophenotype, and cell cycle/growth activation marker expression in sporadic and neurofibromatosis 1-related lesions. Am J Surg Pathol 2003;27:13371345.

26 Weiss SW, Goldblum JR. Enzinger and Weiss's Soft Tissue Tumors, 4th edn. St Louis: Mosby, 2001.

27 Daniels MJ, Marson A, Venkitaraman AR. PML bodies control the nuclear dynamics and function of the CHFR mitotic checkpoint protein. Nat Struct Mol Biol 2004;11:1114-1121.

28 Rosivatz E, Becker I, Specht K, et al. Differential expression of the epithelial-mesenchymal transition regulators snail, SIP1, and twist in gastric cancer. Am J Pathol 2002;161:1881-1891.

29 Chaturvedi P, Sudakin V, Bobiak ML, et al. Chfr regulates a mitotic stress pathway through its RINGfinger domain with ubiquitin ligase activity. Cancer Res 2002;62:1797-1801.

$30 \mathrm{Yu}$ X, Minter-Dykhouse K, Malureanu L, et al. Chfr is required for tumor suppression and Aurora A regulation. Nat Genet 2005;37:401-406.

31 Bischoff JR, Anderson L, Zhu Y, et al. A homologue of Drosophila aurora kinase is oncogenic and amplified in human colorectal cancers. EMBO J 1998;17: 3052-3065.

32 Sakakura C, Hagiwara A, Yasuoka R, et al. Tumouramplified kinase BTAK is amplified and overexpressed in gastric cancers with possible involvement in aneuploid formation. Br J Cancer 2001;84:824-831.

33 Miyoshi Y, Iwao K, Egawa C, et al. Association of centrosomal kinase STK15/BTAK mRNA expression with chromosomal instability in human breast cancers. Int J Cancer 2001;92:370-373.

34 Meraldi P, Honda R, Nigg EA. Aurora-A overexpression reveals tetraploidization as a major route to centrosome amplification in p53-/ - cells. EMBO J 2002;21:483-492.

35 Wong WW, Hirose T, Scheithauer BW, et al. Malignant peripheral nerve sheath tumor: analysis of treatment outcome. Int J Radiat Oncol Biol Phys 1998;42: 351-360.

36 Adachi T, Oda Y, Sakamoto A, et al. Immunoreactivity of p53, mdm2, and p21WAF1 in dedifferentiated liposarcoma: special emphasis on the distinct immunophenotype of the well-differentiated component. Int J Surg Pathol 2001;9:99-109. 